Research

\title{
Quality of Life determinants in women with breast cancer undergoing treatment with curative intent
} Manoj Pandey*1,3, Bejoy Cherian Thomas1, Padmakumar SreeRekha1, Kunnambath Ramdas ${ }^{2}$, Kuttan Ratheesan ${ }^{2}$, Sankarannair Parameswaran², Beela S Mathew ${ }^{2}$ and Balakrishnan Rajan ${ }^{2}$

Address: ${ }^{1}$ Departments of Surgical Oncology, Regional Cancer Centre, Trivandrum, India, ${ }^{2}$ Department of Radiation Oncology, Regional Cancer Centre, Trivandrum, India and ${ }^{3}$ Department of Surgical Oncology, Jawaharlal Nehru Cancer hospital and Research Centre, Bhopal, India

Email: Manoj Pandey* - manojpandey@vsnl.com; Bejoy Cherian Thomas - bejoyct@rediffmail.com;

Padmakumar SreeRekha - oncosurgery@hotmail.com; Kunnambath Ramdas - oncosurgery@ hotmail.com; Kuttan Ratheesan - oncosurgery@hotmail.com; Sankarannair Parameswaran - oncosurgery@hotmail.com;

Beela S Mathew - oncosurgery@hotmail.com; Balakrishnan Rajan - rajanrcc@satyam.net.in

* Corresponding author

Published: 27 September 2005

World Journal of Surgical Oncology 2005, 3:63 doi:10.1 186/1477-7819-363

This article is available from: http://www.wjso.com/content/3///63

(c) 2005 Pandey et al; licensee BioMed Central Ltd.

This is an Open Access article distributed under the terms of the Creative Commons Attribution License (http://creativecommons.org/licenses/by/2.0), which permits unrestricted use, distribution, and reproduction in any medium, provided the original work is properly cited.
Received: 10 June 2005

Accepted: 27 September 2005

\begin{abstract}
Background: The diagnosis of breast cancer and its subsequent treatment has significant impact on the woman's physical functioning, mental health and her well-being, and thereby causes substantial disruption to quality of life (QOL). Factors like patient education, spousal support and employment status, financial stability etc., have been found to influence $\mathrm{QOL}$ in the breast cancer patient. The present study attempts to identify the determinants of QOL in a cohort of Indian breast cancer patients.
\end{abstract}

Patients and methods: Functional Assessment of Cancer Therapy-Breast (FACT-B) Version 4 Malayalam was used to assess quality of life in 502 breast cancer patients undergoing treatment with curative intent. The data on social, demographic, disease, treatment, and follow-up were collected from case records. Data was analysed using Analysis of Variance (ANOVA) and multinomial logistic regression.

Results: The mean age of the patients was 47.7 years with $44.6 \%$ of the women being pre-menopausal. The FACT-B mean score was 90.6 (Standard Deviation $[S D]=18.4$ ). The mean scores of the subscales were - Physical well-being 19.6 (SD = 4.7), Social well-being 19.9 (SD = 5.3), Emotional well-being I4 (SD $=4.9)$, Functional well-being I3.0 (SD = 5.7), and the Breast subscale $23.8(\mathrm{SD}=4.4)$. Younger women ( $<45$ years), women having unmarried children, nodal and/or metastatic disease, and those currently undergoing active treatment showed significantly poorer QOL scores in the univariate analysis. However multivariate analysis indicated that the religion, stage, pain, spouse education, nodal status, and distance travelled to reach the treatment centre as indicative of patient QOL.

Conclusion: QOL derangements are common in breast cancer patients necessitating the provisions for patient access to psychosocial services. However, because of the huge patient load, a screening process to identify those meriting intervention over the general population would be a viable solution. 


\section{Background}

Breast cancer is the leading cause of cancer death among women around the world. In India it shows mix incidence pattern with breast cancer being second to cancer of the cervix in rural areas $[1,2]$, however, in metropolitan cities like Mumbai, New Delhi and Trivandrum, the incidence of breast cancer has crossed that of cervix. The incidence of breast cancer in India ranges from 8.8/100,000 at Barshi to 28.6/100,000 at Mumbai [2]. In Trivandrum, the age-adjusted-rate (AAR) is $31.7 / 100,000$ for the urban population and 16.5/100,000 for rural population [3].

The focus of breast cancer care, in addition to examining short-term treatment related quality of life (QOL) outcomes, has expanded to include acute treatment-related side effects and long-term factors that influence the qual- ity as well as quantity of survival [4-7]. Considerable efforts are directed to reduce morbidity from treatment and rehabilitation. Scenario in India is little different. In absence of screening programmes, majority of the breast cancers are still diagnosed in locally advanced stage and achieving longer survival is still a priority. A few studies on QOL in the Indian context exist, factors like patient education, spousal support and employment status, financial stability, disease stage, etc., have been found to influence patient QOL $[8,9]$.

QOL domains like levels of physical, social, and psychological well-being have been found to be comparable to those of women without the disease $[10,11]$. Initially, women with breast cancer, especially younger women, tend to suffer substantial disruption in their physical func-

Table I: Frequency and percentage distribution of demographic characteristics of study population

\begin{tabular}{|c|c|c|c|c|}
\hline Variable & Grouping Codes & Group & $N$ & Percentage \\
\hline \multirow[t]{2}{*}{ Interviewer } & I & BCT & 197 & $39.2 \%$ \\
\hline & 2 & SR & 305 & $60.8 \%$ \\
\hline \multirow[t]{3}{*}{ Social class } & 1 & Low & 167 & $33.3 \%$ \\
\hline & 2 & Middle & 164 & $32.7 \%$ \\
\hline & 3 & High & 171 & 34.1 \\
\hline \multirow[t]{5}{*}{ Distance to centre $(\mathrm{Km})$} & I & Local & 150 & $29.9 \%$ \\
\hline & 2 & $<150$ & 241 & $48.0 \%$ \\
\hline & 3 & $<150-250$ & 61 & $12.2 \%$ \\
\hline & 4 & $>250$ & 49 & $9.8 \%$ \\
\hline & 5 & Don't know & 1 & $0.2 \%$ \\
\hline \multirow[t]{4}{*}{ Religion } & I & Hindu & 323 & $64.3 \%$ \\
\hline & 2 & Muslim & 71 & $14.1 \%$ \\
\hline & 3 & Christian & 94 & $18.7 \%$ \\
\hline & 9 & Others/Don't know & 13 & $2.6 \%$ \\
\hline \multirow{3}{*}{ Marital status } & I & Single & 23 & $4.6 \%$ \\
\hline & 2 & Married & 377 & $75.1 \%$ \\
\hline & 3 & Widow/Divorce & 100 & $19.9 \%$ \\
\hline \multirow[t]{6}{*}{ Self education } & I & Illiterate & 23 & $4.6 \%$ \\
\hline & $\underline{2}$ & $\leq 5$ & 96 & $19.1 \%$ \\
\hline & 3 & $6-10$ & 255 & $50.8 \%$ \\
\hline & 4 & $11-12$ & 55 & $11.0 \%$ \\
\hline & 5 & Graduate/tech & 40 & $8.0 \%$ \\
\hline & 6 & Post graduate & 29 & $5.8 \%$ \\
\hline \multirow[t]{7}{*}{ Spouse education } & I & Illiterate & 12 & $2.4 \%$ \\
\hline & $\underline{2}$ & $\leq 5$ & 64 & $12.7 \%$ \\
\hline & $\overline{3}$ & $6-10$ & 198 & $39.4 \%$ \\
\hline & 4 & $11-12$ & 26 & $5.2 \%$ \\
\hline & 5 & Graduate/tech & 44 & $8.8 \%$ \\
\hline & 6 & Post graduate & 31 & $6.2 \%$ \\
\hline & 7 & Don't know & 127 & $25.3 \%$ \\
\hline \multirow[t]{4}{*}{ Self Occupation } & I & HW/Unemployed & 380 & $75.7 \%$ \\
\hline & 2 & Employed & 81 & $16.1 \%$ \\
\hline & 3 & Self/Business/Daily & 31 & $6.2 \%$ \\
\hline & 9 & Don't know & 10 & $2.0 \%$ \\
\hline \multirow[t]{4}{*}{ Spouse Occupation } & I & HW/Unemployed & 50 & $10 \%$ \\
\hline & 2 & Employed & 135 & $26.9 \%$ \\
\hline & 3 & Self/Business/Daily & 170 & $33.9 \%$ \\
\hline & 9 & Don't know & 146 & $29.1 \%$ \\
\hline
\end{tabular}


tioning, mental health and well-being $[12,13]$. Due to this wide variability in QOL $[14,15]$ identification of factors that render women vulnerable to negative outcomes and poor QOL is essential [6]. This study aims at identifying the determinants of QOL of Indian women with breast cancer treated with curative intent, on a cross-sectional cohort of patients interviewed at a single cancer care centre.

\section{Patients and Methods}

The study sample consisted of 504 breast cancer patients who were undergoing or had undergone curative treatment at our centre. The tool was administered either at the beginning of the treatment or at follow-up after the treatment. The earlier validated local language version [8] of the Functional Assessment of Cancer Therapy-Breast, Version 4 (FACT-B) [16] was used. FACT-B is a 36 item self administered scale containing 4 general subscales i.e. physical, social/family well being, functional and emotional well being, the fifth subscale contain 9 items and is specific for breast cancer. Written consent was obtained from all the patients prior to administering the tool. The study was approved by the Institutional research board and the Ethics committee. The test was administered and scored in accordance with the instructions in the manual for the Version 4 of the Functional Assessment of Chronic Illness Therapy (FACIT) Measurement System [17]. Group comparisons were carried out by using one-way analysis of variance (ANOVA). Multivariate analysis was carried out using multiple logistic regression, the data was dichotomised using the median value and factors identified by literature search, and univariate analysis were entered into the model in single step (step method).

\section{Results}

Mean age of the patients was 47.6 years ( $\mathrm{SD}=11$, range 20-80, median 47 years). Of the 502 patients almost equal number belonged to upper, middle and lower class (Table 1). Majority of the patients were Hindus (78\%) resided within $150 \mathrm{~km}$ of the centre and most were married $(75 \%)$. Other population characteristics are described in table 1.

Over $90 \%$ of the patients had been diagnosed prior to being referred to tertiary centre for treatment and $22 \%$ of them had underwent surgery in form of either modified radical mastectomy or breast conservation elsewhere

Table 2: Frequency and percentage distribution of disease characteristics in patients

\begin{tabular}{|c|c|c|c|c|}
\hline Variable & Grouping Codes & Group & $N$ & Percentage \\
\hline \multirow[t]{4}{*}{ Symptoms } & I & Lump & 426 & $84.9 \%$ \\
\hline & 2 & Ulcer & 3 & $0.6 \%$ \\
\hline & 3 & Discharge & 28 & $5.6 \%$ \\
\hline & 9 & Don't know & 44 & $8.8 \%$ \\
\hline \multirow[t]{3}{*}{ Pain } & I & Yes & 133 & $26.5 \%$ \\
\hline & 2 & No & 334 & $66.5 \%$ \\
\hline & 3 & Don't know & 35 & $7.0 \%$ \\
\hline \multirow[t]{4}{*}{ How diagnosed } & I & Biopsy & 212 & $42.2 \%$ \\
\hline & 2 & FNAC & 239 & $47.6 \%$ \\
\hline & 3 & Mammogram only & 4 & $0.8 \%$ \\
\hline & 9 & Don't know & 46 & $9.2 \%$ \\
\hline \multirow[t]{5}{*}{ Previous Treatment } & 0 & Nil & 218 & $43.4 \%$ \\
\hline & I & Excision & 84 & $16.7 \%$ \\
\hline & 2 & MRM & 110 & $21.9 \%$ \\
\hline & 3 & $\mathrm{BCT}$ & 2 & $0.4 \%$ \\
\hline & 9 & Don't know & 88 & $17.6 \%$ \\
\hline \multirow[t]{5}{*}{ Tumour staging } & I & $T_{1}$ & 33 & $6.6 \%$ \\
\hline & 2 & $\mathrm{~T}_{2}$ & 174 & $34.7 \%$ \\
\hline & 3 & $\mathrm{~T}_{3}$ & 80 & $15.9 \%$ \\
\hline & 4 & $\mathrm{~T}_{4}$ & 76 & $15.1 \%$ \\
\hline & 9 & $T_{X}$ & 139 & $27.7 \%$ \\
\hline \multirow[t]{5}{*}{ Nodal involvement } & 0 & $\mathrm{~N}_{0}$ & 140 & $27.9 \%$ \\
\hline & 1 & $\mathrm{~N}_{1}$ & 166 & $33.1 \%$ \\
\hline & 2 & $\mathrm{~N}_{2}$ & 43 & $8.6 \%$ \\
\hline & 3 & $\mathrm{~N}_{3}$ & 4 & $8.0 \%$ \\
\hline & 9 & $\mathrm{~N}_{\mathrm{X}}$ & 149 & $29.7 \%$ \\
\hline
\end{tabular}

FNAC: Fine needle aspiration cytology; BCT: Breast conservation treatment; MRM: Modified radical mastectomy. 
Table 3: Mean, standard deviation, median and range of the QOL scale, subscale scores and patient age.

\begin{tabular}{llll}
\hline Parameter & Mean \pm SD & Median & Range \\
\hline Age & $47.65 \pm 11$ & 47 & $20-80$ \\
General Physical well-being (GP) & $19.8 \pm 4.7$ & 20 & $3-28$ \\
General Social well-being (GS) & $19.9 \pm 5.3$ & 20.5 & $2.8-28$ \\
General Emotional well-being (GE) & $14 \pm 4.9$ & 14 & $1-24$ \\
General Functional well-being (GF) & $13 \pm 5.7$ & 12 & $2-28$ \\
Breast specific subscale (B) & $23.7 \pm 4.3$ & 24.8 & $10-34.7$ \\
Total FACT-B score & $90.5 \pm 18.4$ & 87 & $38-136.5$ \\
\hline
\end{tabular}

(Table 2). Most of the patients had $\mathrm{T}_{2}$ disease (34.7\%) followed by $\mathrm{T}_{3}(16 \%)$ and $\mathrm{T}_{4}(15 \%)$. Axillary nodes were present in $42 \%$ of the sample (Table 2 ).

The over all mean $( \pm \mathrm{SD})$ quality of life score was 90.5 $( \pm 18.4)$ (median 87$)$ ranging from 38-136.5. Mean score for various subscales were: physical well-being (GP) 19.8 \pm 4.7; social family well-being (GS) $19.9 \pm 5.3$; Emotional well-being (GE) $14 \pm 14.9$ and functional well-being (GF) $13 \pm 5.7$. The mean scores for breast subscale was $23.07 \pm$ 4.3 (median 24.8 range 10-34.7). The median and score range is detailed in table 3 . The mean $( \pm \mathrm{SD})$ subscale and scale scores for various variables are detailed in additional tables 1 and 2.

On univariate analysis, patient's education $(\mathrm{p}=0.004)$, spouse occupation $(0.01)$, number of children $(p=0.02)$, previous treatment $(p=0.02)$, nodal stage $(p=0.03)$, metastasis $(\mathrm{p}=0.000)$ and composite stage $(\mathrm{p}=0.000)$ of the disease were found to influence physical well-being (additional file 1).

The distance travelled to reach the treatment centre $(\mathrm{p}=$ $0.04)$, religion of the patient $(\mathrm{p}=0.006)$ marital status ( $\mathrm{p}$ $=0.002)$, education $(\mathrm{p}=0.04)$ self $(\mathrm{p}=0.02)$ and spouse occupation $(0.04)$, method of diagnosis $(p=0.000)$, previous treatment $(\mathrm{p}=000)$ and nodal status $(\mathrm{p}=0.02)$ were found to significant influence emotional well-being.

Functional well-being was found to be influenced by religion $(\mathrm{p}=0.000)$, patients education $(\mathrm{p}=0.000)$, self $(\mathrm{p}=$ $0.000)$ and spouse occupation ( $p=0.001)$, mode of diagnosis $(\mathrm{p}=0.01)$, previous treatment $(\mathrm{p}=0.02)$, and nodal status $(\mathrm{p}=0.01)$. While distance travelled to the centre $(\mathrm{p}$ $=0.003$ ) patients education, mode of diagnosis, previous treatment, presence of metastasis and composite stage significantly influenced breast specific subscale.

The overall quality of life was found be significantly affected by income $(\mathrm{p}=0.03)$, Religion $(\mathrm{p}=0.005)$, patients education $(\mathrm{p}=0.000)$, self $(\mathrm{p}=0.004)$ and spouse occupation $(\mathrm{p}=0.000)$ presence of pain $(\mathrm{p}=$
$0.001)$, method of diagnosis $(\mathrm{p}=0.000)$, previous treatment $(\mathrm{p}=0.02)$, nodal stage $(\mathrm{p}=0.01)$, presence of metastasis $(\mathrm{p}=0.04)$ and composite stage $(\mathrm{p}=0.005)$ (additional file 1).

\section{Result of multiple logistic regression}

Additional file 2 shows results of multivariate analysis. Distance travelled to the treatment centre and presence of nodal metastasis at initial presentation was found to significantly influence physical well-being. Social and family well-being was affected by religion. Emotional well-being was significantly influenced by religion and tumour stage at presentation. Functional well-being was influenced by religion, presence or absence of pain and tumour stage at presentation. While education of spouse was found to influence breast specific subscale, the overall quality of life was found to be significantly influenced by religion and tumour stage of the disease at presentation (Figure 1).

\section{Discussion}

In India, comprehensive cancer care is provided in the tertiary care centres and due to fewer numbers of such centres there are ever increasing patient load on each of them. Most patients present in locally advanced stage and achieving a good survival is still a priority. However, a few attempts have been made to comprehend and address the psychological and social needs of cancer patients $[8,18,19]$.

The state of Kerala has a unique distinction of being $90 \%$ literate and having more females than males in the society [20]. However, as the state offers few employment opportunities, the per-capita income is low, and migration to other states and countries is high. It is also seen as a borrower's economy and is often termed as a consumer state. All these factors contribute to the state's high cost of living despite poor average earnings. Hence, developing a chronic illness or having a spouse with chronic illness like cancer would mean loss of that day's income, and extra expenditures. This reflects in the present study as well as the family income was found to significantly influence the overall quality of life. 


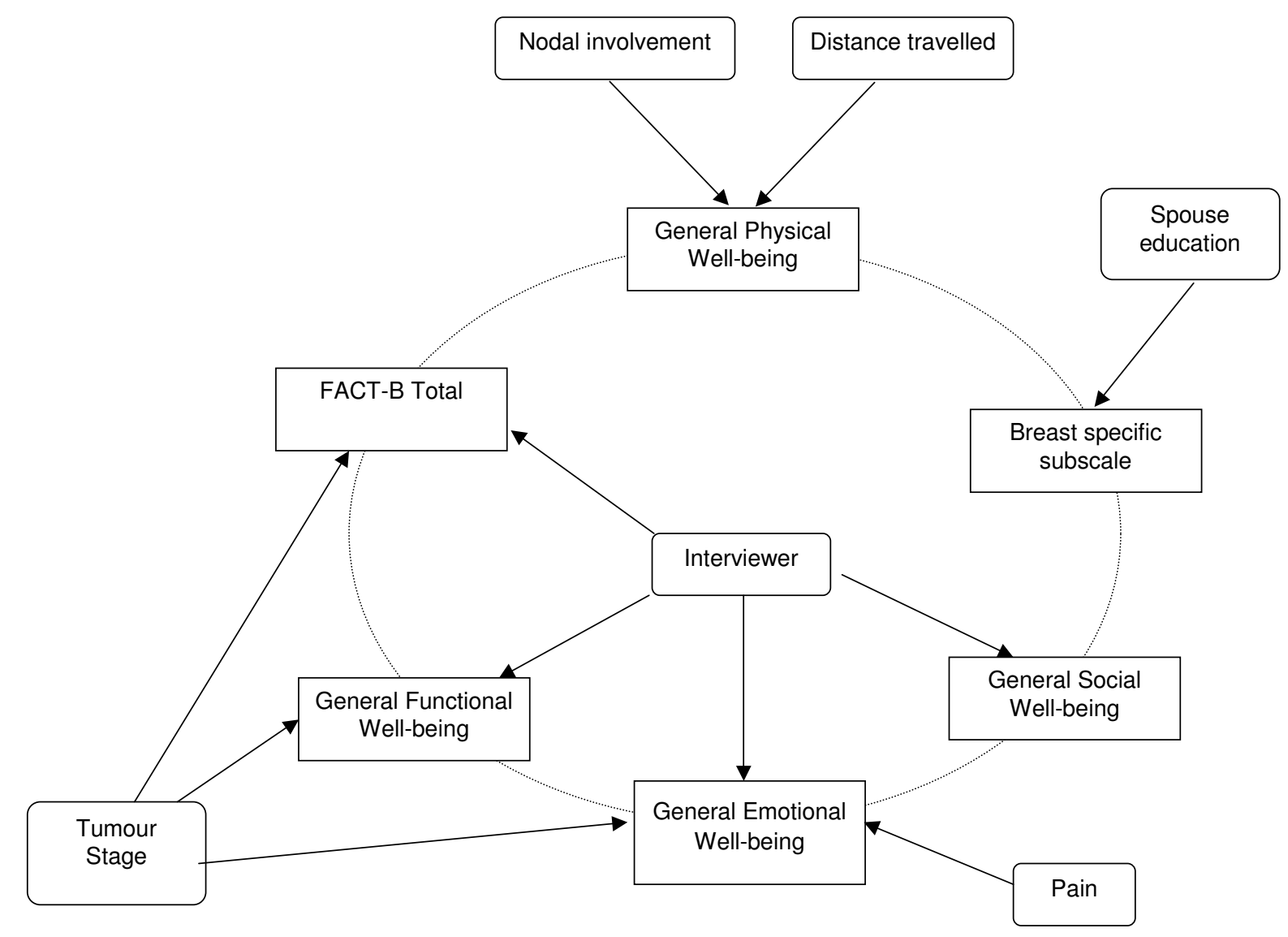

Figure I

Factors influencing quality of life of women with breast cancer in India identified using logistic regression.

Initial diagnosis has been shown to evoke a state of shock, fear and disbelief [21] thus creating not only a psychological crisis but an existential one as well [22]. Education has been found to significantly help one cope with these situations. In the present study too, the education was found to be a significant predictor of overall QOL in univariate analysis, however this significance was lost in the multivariate analysis. Spouse education was found to significantly influence social well-being in the univariate analysis, however in multivariate analysis it was found to significantly influence the breast specific subscale.

Culturally, Indian parents are substantially involved in their offspring's personal and social development, education, and more importantly their marriage, as majority of the marriages are arranged. Such marriages are stressful particularly for the parents of girls. Issues around dowry, sometimes described as a "social evil", play a significant determining role in marriage alliances. Adding the taboo of a parent with cancer affords even greater psychological pressure and financial burden on a family with unmarried children. This is more in patients with lower and middle income where the resources are meagre. The diagnosis of a cancer in the family also has its social stigma, which may influence the marriage prospects of the children. This is reflected in the results of the present study where number of unmarried children was found to significantly affect emotional well-being.

The present study has identified several factors that influence the QOL of the Indian breast cancer patient. Presence of pain has been identified to significantly influence phys- 
ical well-being and overall QOL, stage of disease has been identified to influence functional well-being and breast specific subscale. In the univariate analysis, the distance travelled by a patient to the treatment centre significantly influenced the breast specific QOL and emotional wellbeing, however in the multivariate analysis it was found to significantly influence only the patient's physical wellbeing as expected. It was also interesting to note that though the univariate analysis did not indicate 'tumour stage' as an indicator of QOL in the breast cancer patient, the multivariate analysis showed its significant influence on emotional and functional well-being as well as on over all QOL score. In contrast to this, 'nodal involvement' was noted to influence the physical, emotional, functional well-being, and overall QOL score in the univariate analysis, but was found to significantly influence only the patients physical well-being in multivariate analysis. Several other variables that were found to have significant effect on quality of life and subscales in the univariate analysis turned out as insignificant in the multivariate analysis, viz. gender of the interviewer, and patient occupation etc.

The need for psychosocial intervention amongst cancer patients cannot be understated. The goals of planning a psychosocial intervention in the Indian breast cancer context would be to support the patient's ability to cope with the stress of treatment, helping them to tolerate shortterm loss for long-term gain, and to assist in symptom management [21,24-26]. However, owing to increased patient burden, in-depth psychological intervention to each patient may not be feasible, and some sort of mechanism to cater to psychosocial problems need to be identified. Identification of the subset of women at risk is one such way forward, followed by targeted intervention that could be in form of patient education and counselling.

\section{Competing interests}

MP is the editor-in-chief of World Journal of Surgical Oncology, published by Open Access publishers Biomedcentral, which depends on Open Access model for substantial portion of its revenue.

\section{Ethical approval}

The study is approved by the institutional review board and the ethics committee.

\section{Authors' contributions}

MP: designed and coordinated the study, participated in statistical analysis, helped in preparing the draft manuscript and edited the final version for publication, beside contribution to patient management.

BCT: Participated in the study, data collection and statistical analysis and drafted the manuscript
PS: Participated in data collection and preparation of the manuscript

KR, KR, SP, BSM and BR contributed in patient management, study design and conduct and interpretation of results. They also contributed to the intellectual content of the manuscript.

All the authors read and approved the final version of the manuscript for publication

MP and KR are the guarantors of the manuscript

\section{Additional material}

\section{Additional file 1}

QOL Breast 2005 showing results of univariate analysis.

Click here for file

[http://www.biomedcentral.com/content/supplementary/1477-

7819-3-63-S1.doc]

\section{Additional file 2}

QOL breast 2005 showing results of multivariate analysis, multivariate odds ratios and $p$ values.

Click here for file

[http://www.biomedcentral.com/content/supplementary/1477-

7819-3-63-S2.doc]

\section{Acknowledgement \& Funding}

This study is funded by a generous grant from the Indian Council of Medical Research (ICMR) New Delhi, India vide grant number 5//3/74/2000/ NCD-III. The funding organisation had no role is study design. The study is independent from the funders.

\section{References}

I. Parkin DM, Whelan SL, Ferlay J, Raymond L, Young J, (eds): Cancer incidence in five continents Volume VII. International agency for research on cancer, Lyon, France. IARC Sci Pub No. I43; 1997.

2. National Cancer Registry Programme: Biennial Report (1988-89): An epidemilogical study Indian Council of Medical Research, New Delhi; 1992.

3. Mathew A, Vijayaprasad B: Cancer incidence and mortality in Trivandrum (1998-1999), population based cancer registry Regional Cancer Centre, Trivandrum; 2002.

4. Ferrell BR, Grant M, Funk B, Otis-Green S, Garcia N: Quality of life in breast cancer - Part II: psychological and spiritual wellbeing. Cancer Nursing 1998, 2 I: I-9.

5. Cella DF, Bonomi AE: Measuring QOL: 1995 update. Oncology 1995, 9:47-60.

6. Stanton AL, Krishnan L, Collins CA: Form or function? Part I. Subjective cosmetic and functional correlates of quality of life in women treated with breast-conserving surgical procedures and radiotherapy. Cancer 200I, $91: 2273-2281$.

7. Krishnan L, Stanton AL, Collins CA, Jewell WR: Form or function? Part 2. Objective cosmetic and functional correlates of quality of life in women treated with breast-conserving surgical procedures and radiotherapy. Cancer 200I, 9 I:2282-2287.

8. Pandey M, Thomas BC, Ramdas K, Eremenco S, Nair MK: Quality of life in breast cancer patients: validation of a FACT-B Malayalam version. Qual Life Res 2002, I I:87-90. 
9. Pandey M, Singh SP, Behere PB, Roy SK, Singh S, Shukla VK: Quality of life in patients with early and advanced carcinoma of the breast. Eur J Surg Oncol 2000, 26:20-24.

10. Vinokur AD, Threatt BA, Caplan RD, Qimmerman BL: Physical and psychosocial functioning and adjustment to breast cancer: long-term follow-up of a screening population. Cancer 1989, 63:394-405.

II. Ganz PA, Rowland JH, Desmond K, Meyerowitz BE, Wyatt GE: Life after breast cancer: understanding women's health-related quality of life and sexual functioning. J Clin Oncol 1998, 16:50I-5I4.

12. Vinokur AD, Threatt BA, Vinokur-Kaplan D, Satariano WA: The process of recovery from breast cancer for younger and older patients: changes during the first year. Cancer 1990, 65: $1242-1254$

13. Levy SM, Haynes LT, Herberman RB, Lee J, McFeeley S, Kirkwood J: Mastectomy versus breast cinservation surgery: mental health effects at long-term follow-up. Health Psychol 1992, I I:349-354.

14. Derogatis LR, Morrow GR, Fetting J, Penman D, Piasetsky S, Schmale AM, Henrichs M, Carnicke CL Jr: The prevalence of psychiatric disorders among cancer patients. JAMA 1983, 249:75I-757.

15. Stanton AL, Snider PR: Coping with a breast cancer diagnosis: a prospective study. Health Psychology 1993, 12:16-23.

16. Brady MJ, Cella DF, Mo F, Bonomi AE, Tulsky DS, Lloyd SR, Deasy S, Cobleigh M, Shiomoto G: Reliability and validity of the Functional Assessment of Cancer Therapy-Breast quality-of-life instrument. J Clin Oncol 1997, 15:974-986.

17. FACIT Manual: Manual of the Functional Assessment of Chronic Illness Therapy (FACIT) Measurement System Version 4 Edited by: Cella D. CORE, Evanston Northwestern Healthcare, Evanston, IL, USA; 1997.

18. Thomas BC, Nandamohan V, Thomas I, Pandey M: Psychological distress among cancer patients: Development of a distress inventory for cancer. J Postgrad Med 2002, 48:16-20.

19. Pandey M, Thomas BC: Rehabilitation of cancer patients. J Postgrad Med 200I, 47:62-65.

20. Census of India: 200I Census results. [http://www.censusin dia.net/literates I.html].

21. Holland JC, Gooen-Piels J: Principles of Psycho-Oncology. In Cancer Medicine 5th edition. Edited by: Bast RC, Kufe DW, Pollock RE, Weichselbaum RR, Holland JF, Frei E. BC Decker, Ontario; 2000.

22. Thomas BC, Pandey M, Ramdas K, Nair MK: Psychological distress in cancer patients: Hypothesis of a distress model. Eur J Cancer Prev 2002, II: I79-185.

23. Ganz PA, Hirji K, Sim MS, Schag CA, Fred C, Polinsky ML: Predicting psychosocial risk in patients with breast cancer. Med Care 1993, 31:419-431.

24. Jacobsen PB, Bovbjerg DH, Schwartz MD, Hudis CA, Gilewski TA, Norton L: Conditioned emotional distress in women receiving chemotherapy for breast cancer. J Consult Clin Psychol 1995, 63:108-114.

25. van't Spijker A, Trijsburg RW, Duivenvoorden HJ: Psychological sequelae of cancer diagnosis: a meta-analytical review of 58 studies after 1980. Psychosom Med 1997, 59:280-293.

26. Payne DK, Sullivan MD, Massie MJ: Women's psychological reactions to breast cancer. Semin Oncol 1996, 23:89-97.

\section{Publish with Bio Med Central and every} scientist can read your work free of charge

"BioMed Central will be the most significant development for disseminating the results of biomedical research in our lifetime. "

Sir Paul Nurse, Cancer Research UK

Your research papers will be:

- available free of charge to the entire biomedical community

- peer reviewed and published immediately upon acceptance

- cited in PubMed and archived on PubMed Central

- yours - you keep the copyright
BioMedcentral 